\title{
Computerized Victoria Stroop Test in Adult Unipolar Depressed Patients and Healthy Subjects: Influence of Age and Gender
}

\author{
Marco Moniz ${ }^{1,2,3,4^{*}}$, Saul Neves de Jesus ${ }^{3,4}$, Eduardo Gonçalves ${ }^{1}$, João Viseu ${ }^{3,4}$, \\ Ana Sofia Baptista1, Andreia Pacheco ${ }^{1,5}$ \\ ${ }^{1}$ Department of Psychiatry and Mental Health, Hospital Center of Algarve, Faro, Portugal \\ ${ }^{2}$ António Silva Leal Foundation, Lisboa, Portugal \\ ${ }^{3}$ Faculty of Human and Social Sciences, University of Algarve, Faro, Portugal \\ ${ }^{4}$ Research Centre for Spatial and Organization Dynamics (CIEO), Faro, Portugal \\ ${ }^{5}$ Centre for Biomedical Research (CBMR), Faro, Portugal \\ Email: *emmoniz@gmail.com
}

Received 30 October 2015; accepted 2 January 2016; published 5 January 2016

Copyright (C) 2016 by authors and Scientific Research Publishing Inc.

This work is licensed under the Creative Commons Attribution International License (CC BY).

http://creativecommons.org/licenses/by/4.0/

(c) (i) Open Access

\begin{abstract}
Alterations in executive functioning are frequent in depressive patients, being the common appearance of difficulties in inhibitory control. This study aimed to compare the performance of 31 non-psychotic unipolar depressed subjects ( 22 women and 9 men, with a mean age of 43.81 years old [ $S D=14.78]$ ) to 31 healthy controls ( 21 women and 10 men, with a mean age of 42.77 years old $[S D=13.94]$ ) in a computerized version of Victoria Stroop Test (VST), an instrument that assessed the inhibitory control. Significant differences between depressed patients and healthy controls are concerning time to complete dots, neutral words and color words, as well as in interference trial. A clear influence of the variable age in both groups was also identified, having older subjects (over 50 years old) exhibited slower performances, showing a shared variance between $40 \%$ and $55 \%$ regarding depressive subjects and between $31 \%$ and $55 \%$ concerning healthy controls.
\end{abstract}

\section{Keywords}

Unipolar Depression, Victoria Stroop Test (VST), Inhibitory Control, Normative Data

${ }^{*}$ Corresponding author.

How to cite this paper: Moniz, M., de Jesus, S. N., Gonçalves, E., Viseu, J., Baptista, A. S., \& Pacheco, A. (2016). Computerized Victoria Stroop Test in Adult Unipolar Depressed Patients and Healthy Subjects: Influence of Age and Gender. Psychology, 7, 1-5. http://dx.doi.org/10.4236/psych.2016.71001 


\section{Introduction}

Inhibitory control is an important cognitive function associated with executive functioning and it is assessed with tasks such as Stroop (Miyake et al., 2000). Alterations in execution time (Gohier et al., 2009), as well as in interference (Harvey et al., 2004; Stordal et al., 2004), are common in depression. Concerning unipolar depressed patients, rostral anterior cingulate gyrus (rACG) and left dorsolateral prefrontal cortex (DLPFC) is involved in interference (Wagner et al., 2006).

This study utilized a computerized version of the Victoria Stroop Test (VST) that took less time to be applied and could be found in public domain. According to literature (Gohier et al., 2009; Harvey et al., 2004; Stordal et al., 2004), we hypothesized that depressed patients would be outperformed by healthy controls and that younger subjects would perform faster in both groups, being execution time influenced by age. Performance of depressive patients tended to improve during the course of antidepressant treatment (Wagner, Doering, Helmreich, Lieb, \& Tadić, 2012), however, in the current study, it was not possible to assess drug-free depressed subjects.

The current study aimed to compare the performance of a clinical sample of unipolar depressed patients with adult healthy controls in a computerized version of VST and also provide initial normative data in order to allow its application in clinical contexts and future research.

The importance of this study will be to increase understanding on cognitive functioning of unipolar depressed patients (without any influence of depressive disorders with manic and psychotic symptoms [e.g., bipolar and schizoaffective]). Also, we hope it can provide initial normative data, in order to be a resource widely used by clinicians.

\section{Method}

\subsection{Participants}

Both studied samples, experimental and control groups, were comprised of 31 subjects each. The experimental (patients') group was composed of 22 women and 9 men, with a mean age of 43.81 years old $(S D=14.78)$, a mean of $8.32(S D=3.41)$ years of education and an age range of 17 - 67 years old. The participants from this group were recruited in the city of Faro (Portugal), more precisely from the Department of Psychiatry and Mental Health of Hospital Center of Algarve (a state owned entity). With analogous characteristics, healthy controls comprised 21 women and 10 men, with a mean age of 42.77 years old $(S D=13.94)$, a mean of $9.67(S D=3.79)$ years of education and an age range of $17-67$. Patients and controls did not differ significantly regarding gender $\left(\chi^{2}=.076, d f=1, p=.783\right)$, age $(t=.278, d f=60, p=.782, d=.071)$, and education $(t=-1.792, d f=60, p$ $=.078, d=-.374)$.

Statistically, participants were divided into three age groups: (a) 17 - 39; (b) 40 - 49; and over 50 years old. All participants were Caucasians and Portuguese speakers.

\subsection{Materials}

A computerized VST (Mueller, 2013), from the Psychology Experiment Building Language (PEBL), a free access battery (Mueller \& Piper, 2014) was used, as it is similar to the paper and pencil format (Troyer, Leach, \& Strauss, 2006). The same computer running Microsoft Windows 8.1 and a keyboard were used with all subjects. Keys 1, 2, 3, and 4 were used to perform the selections. Instructions provided by Strauss, Sherman, \& Spreen (2006) were followed for VST application.

\subsection{Procedures}

All participants were assessed individually by a psychologist specifically certified for the purpose. Each participant completed a health and demographic questionnaire and depression diagnoses were confirmed through the MINI (Mini International Neuropsychiatric Interview) (Sheehan et al., 1997) and the BSI (Brief Symptom Inventory) (Canavarro, 2007). Exclusion criteria were current or prior history of bipolar disorders, schizophrenia, major psychosis, substance abuse, dementia, and neurologic disease, including head injury involving a loss of consciousness. To discard malingering, Rey 15-Item Memory Test (15-IMT) was used (Simões et al., 2010).

This study was approved by the Hospital Center of Algarve Ethics Committee, in conformity with the Helsinki declaration. After being provided with all the information about the study, all participants signed an informed consent statement. 
All analyzes were conducted using the Statistical Package for the Social Sciences (SPSS), version 20.0. The level of significance was set at $p<.05$.

\section{Results}

Differences between total scores of depressed subjects and healthy controls in the trials time to complete dots $(t$ $=-3.852, d f=58, p=.001, d=-.994)$, time to complete neutral words $(t=-3.852, d f=58, p=.001, d=-.994)$, time to complete color words $(t=-3.852, d f=58, p=.001, d=-.994)$ and interference $(t=-3.852, d f=58, p$ $=.001, d=-.994)$ were found (Table 1 ).

A one-way analysis of variance (ANOVA) showed significant group differences regarding age (depression dots: $F(2,28)=9.65, p=.001, \eta_{p}^{2}=.408$; neutral words: $F(2,20)=9.33, p=.001, \eta_{p}^{2}=.410$; color words: $F(2,13)=11.10, p=.001, \eta_{p}^{2}=.452$; interference: $F(2,17)=5.35, p=.015, \quad \eta_{p}^{2}=.281$ vs. healthy Dots: $F(2,17)=11.39, p=.001, \eta_{p}^{2}=.431$; neutral words: $F(2,28)=6.15, p=.006, \eta_{p}^{2}=.305$; color words: $F(2,28)$ $=6.31, p=.005, \eta_{p}^{2}=.311$ ), having older subjects (over 50 years old) exhibited slower performances. $T$-tests demonstrated significant group differences concerning gender regarding only healthy subjects in trials time to complete dots $(t=2.380, d f=29, p=.024, d=.967)$ and neutral words $(t=2.607, d f=29, p=.014, d=1.062)$.

We found a shared variance between $40 \%$ and $44 \%$ concerning execution time in depressed subjects (dots: $R^{2}$ $=.435, F(1,29)=22.28, p=.001$; neutral words: $R^{2}=.448, F(1,29)=23.53, p=.001$ and color words: $R^{2}=.408$, $F(1,29)=20.02, p=.001)$ and between $31 \%$ and $55 \%$ in healthy subjects (dots: $R^{2}=.557, F(1,29)=36.52, p$ $=.001$; neutral words: $R^{2}=.482, F(1,29)=27.03, p=.001$ and color words: $R^{2}=.314, F(1,29)=13.30, p$ $=.001)$.

Table 1. Descriptive statistics $(N=62)$.

\begin{tabular}{|c|c|c|c|c|c|c|c|c|}
\hline & \multicolumn{6}{|c|}{ Time } & \multirow{2}{*}{\multicolumn{2}{|c|}{ Interference }} \\
\hline & \multicolumn{2}{|c|}{ Dots } & \multicolumn{2}{|c|}{ Neutral Words } & \multicolumn{2}{|c|}{ Color Words } & & \\
\hline & $\mathrm{D}^{\mathrm{a}}$ & $\mathrm{H}^{\mathrm{b}}$ & $\mathrm{D}^{\mathrm{a}}$ & $\mathrm{H}^{\mathrm{b}}$ & $\mathrm{D}^{\mathrm{a}}$ & $\mathrm{H}^{\mathrm{b}}$ & $\mathrm{D}^{\mathrm{a}}$ & $\mathrm{H}^{\mathrm{b}}$ \\
\hline & $M(S D)$ & $M(S D)$ & $M(S D)$ & $M(S D)$ & $M(S D)$ & $M(S D)$ & $M(S D)$ & $M(S D)$ \\
\hline \multicolumn{9}{|l|}{ Age } \\
\hline $17-39$ & $54.9(19.0)$ & $45.8(14.4)$ & $41.1(15.1)$ & 39.7 (17.8) & $56.2(30.2)$ & $48.0(21.0)$ & $2.4(2.2)$ & $0.75(1.2)$ \\
\hline $40-49$ & 99.6 (39.5) & 63.5 (12.9) & $87.0(36.9)$ & $44.9(9.5)$ & $103.6(37.9)$ & $54.6(15.6)$ & $3.1(2.0)$ & $0.75(1.3)$ \\
\hline+50 & $116.0(38.1)$ & $89.3(33.0)$ & $97.0(37.3)$ & $65.2(22.4)$ & $183.5(95.5)$ & 86.0 (36.9) & $6.7(4.4)$ & $2.0(1.7)$ \\
\hline$F$ & 9.650 & $11.396^{*}$ & $9.337^{*}$ & 6.152 & $11.104^{*}$ & 6.316 & $5.352^{*}$ & 2.945 \\
\hline$p$ & .001 & .001 & .001 & .006 & .001 & .005 & .015 & .069 \\
\hline$\eta_{p}^{2}$ & .408 & .431 & .410 & .305 & .452 & .311 & .281 & .174 \\
\hline \multicolumn{9}{|l|}{ Gender } \\
\hline Male & 85.7 (33.5) & 49.7 (18.0) & $78.1(38.2)$ & $37.0(15.2)$ & $108.4(34.0)$ & $49.0(26.2)$ & $4.2(3.5)$ & $1.0(1.2)$ \\
\hline Female & $90.4(45.1)$ & 73.7 (30.1) & $72.2(40.2)$ & $56.3(20.7)$ & $114.3(92.7)$ & $69.9(31.7)$ & 3.9 (3.6) & $1.3(1.7)$ \\
\hline$F$ & .284 & 2.380 & -.374 & 2.607 & .182 & 1.806 & -.187 & .613 \\
\hline$p$ & .778 & .024 & .711 & .014 & .857 & .081 & .853 & .545 \\
\hline$\eta_{p}^{2}$ & .118 & .967 & -.150 & 1.062 & .084 & .718 & -.084 & .203 \\
\hline Total & $89.0(41.6)$ & $65.8(29.0)$ & 74.0 (39.1) & $50.1(20.9)$ & 112.6 (76.9) & $63.2(31.2)$ & $4.0(3.5)$ & $1.2(1.5)$ \\
\hline$t$ & \multicolumn{2}{|c|}{2.551} & \multicolumn{2}{|c|}{2.991} & \multicolumn{2}{|c|}{3.213} & \multicolumn{2}{|c|}{4.015} \\
\hline$p$ & \multicolumn{2}{|c|}{.013} & \multicolumn{2}{|c|}{.004} & \multicolumn{2}{|c|}{.003} & \multicolumn{2}{|c|}{.001} \\
\hline$d$ & \multicolumn{2}{|c|}{.647} & \multicolumn{2}{|c|}{.762} & \multicolumn{2}{|c|}{.841} & \multicolumn{2}{|c|}{1.039} \\
\hline
\end{tabular}

Note: Educ. $=$ Education, $\mathrm{D}=$ Depressive, $\mathrm{H}=$ Healthy, ${ }^{\mathrm{a}} n=31,{ }^{\mathrm{b}} n=31,{ }^{*}$ Brown-Forsythe. 
Table 2. Percentile of healthy and depressed subjects.

\begin{tabular}{|c|c|c|c|c|c|c|c|c|}
\hline & \multicolumn{6}{|c|}{ Time } & \multirow{2}{*}{\multicolumn{2}{|c|}{ Interference }} \\
\hline & \multicolumn{2}{|c|}{ Dots } & \multicolumn{2}{|c|}{ Neutral Words } & \multicolumn{2}{|c|}{ Color Words } & & \\
\hline & $\mathrm{D}^{\mathrm{a}}$ & $\mathrm{H}^{\mathrm{b}}$ & $\mathrm{D}^{\mathrm{a}}$ & $\mathrm{H}^{\mathrm{b}}$ & $\mathrm{D}^{\mathrm{a}}$ & $\mathrm{H}^{\mathrm{b}}$ & $\mathrm{D}^{\mathrm{a}}$ & $\mathrm{H}^{\mathrm{b}}$ \\
\hline 5 & 184.69 & 131.79 & 153.85 & 101.94 & 352.39 & 138.26 & 12,4 & 4 \\
\hline 10 & 167.87 & 107.04 & 143.16 & 76.66 & 205.83 & 118.35 & 9 & 4 \\
\hline 25 & 105.80 & 75.65 & 94.16 & 59.97 & 138.90 & 75.59 & 6 & 3 \\
\hline 50 & 78.20 & 61.04 & 65.37 & 48.16 & 106.25 & 55.67 & 4 & 0 \\
\hline 75 & 58.79 & 49.09 & 41.68 & 39.25 & 49.07 & 41.34 & 1 & 0 \\
\hline 90 & 44.45 & 32.06 & 30.28 & 23.23 & 37.84 & 29.37 & 0 & 0 \\
\hline 95 & 36.11 & 29.78 & 28.57 & 19.59 & 33.59 & 22.25 & 0 & 0 \\
\hline
\end{tabular}

Note: $\mathrm{D}=$ Depressive, $\mathrm{H}=$ Healthy, ${ }^{\mathrm{a}} n=31,{ }^{\mathrm{b}} n=31$.

\section{Discussion}

As in previous studies, there were no significant differences in execution time (cognitive slowness) between depressive subjects and healthy controls (Gohier et al., 2009), despite the first having exhibited a slower performance.

Regarding interference (inhibitory control), corroborating previous research, a difference between groups was found (Harvey et al., 2004; Stordal et al., 2004).

Concerning aging effects, older subjects (over 50 years old) took more time to perform each trial, therefore the influence of the variable age, previously reported in literature (Mitrushina, Boone, Razani, \& D’Elia, 2005; Troyer et al., 2006), was corroborated by the current study.

\section{Conclusion}

One of this study's main contributions is sharing statistical data collected in clinical context to allow other clinicians to use initial normative data (Table 2). It is of outmost significance since VST is an instrument that is not covered by copyright law and of mandatory use to evaluate depressed patients. The main limitation was the size of the sample concerning both patients and healthy controls, which prevented us from validating clearly normative data of this test. Future research comparing wider numbers of subjects and more homogeneous samples—particularly regarding age groups-is therefore recommended.

\section{Acknowledgements}

We thank all participants of this study.

\section{References}

Canavarro, M. C. (2007). Inventário de Sintomas Psicopatológicos (BSI): Uma revisão crítica dos estudos realizados em Portugal. In M. R. Simões, C. Machado, M. M. Gonçalves, \& L. S. Almeida (Eds.), Avaliação Psicológica: Instrumentos Validados para a População Portuguesa (vol. III, pp. 305-330). Coimbra, Portugal: Quarteto Editora.

Gohier, B., Ferracci, L., Surguladze, S. A., Lawrence, E., El Hage, W., Kefi, M. Z., Le Gall, D. et al. (2009). Cognitive Inhibition and Working Memory in Unipolar Depression. Journal of Affective Disorders, 116, 100-105. http://dx.doi.org/10.1016/j.jad.2008.10.028

Harvey, P. O., Le Bastard, G., Pochon, J. B., Levy, R., Allilaire, J. F., Dubois, B., \& Fossati, P. (2004). Executive Functions and Updating of the Contents of Working Memory in Unipolar Depression. Journal of Psychiatric Research, 38, 567-576. http://dx.doi.org/10.1016/j.jpsychires.2004.03.003

Mitrushina, M., Boone, K. B., Razani, J., \& D’Elia, L. F. (2005). Handbook of Normative Data for Neuropsychological Assessment (2nd ed.). Oxford, UK: Oxford University Press.

Miyake, A., Friedman, N. P., Emerson, M. J., Witzki, A. H., Howerter, A., \& Wager, T. D. (2000). The Unity and Diversity 
of Executive Functions and Their Contributions to Complex "Frontal Lobe” Tasks: A Latent Variable Analysis. Cognitive Psychology, 41, 49-100. http://dx.doi.org/10.1006/cogp.1999.0734

Mueller, S. T. (2013). The Psychology Experiment Building Language (Version 0.13) [Software]. http://pebl.sourceforge.net

Mueller, S. T., \& Piper, B. J. (2014). The Psychology Experiment Building Language (PEBL) and PEBL Test Battery. Journal of Neuroscience Methods, 222, 250-259. http://dx.doi.org/10.1016/j.jneumeth.2013.10.024

Sheehan, D., Lecrubier, Y., Harnett Sheehan, K., Janavs, J., Weiller, E., Keskiner, A., Dunbar, G. et al. (1997). The Validity of the Mini International Neuropsychiatric Interview (MINI) According to the SCID-P and Its Reliability. European Psychiatry, 12, 232-241. http://dx.doi.org/10.1016/S0924-9338(97)83297-X

Simões, M., Sousa, L., Duarte, P., Firmino, H., Pinho, M. S., Gaspar, N., França, S. et al. (2010). Avaliação da simulação ou esforço insuficiente com o Rey 15-Item Memory Test (15-IMT): Estudos de validação em grupos de adultos idosos. Análise Psicológica, 28, 209-226.

Stordal, K. I., Lundervold, A. J., Egeland, J., Mykletun, A., Asbjørnsen, A., Landrø, N. I., Lund, A. et al. (2004). Impairment across Executive Functions in Recurrent Major Depression. Nordic Journal of Psychiatry, 58, 41-47. http://dx.doi.org/10.1080/08039480310000789

Strauss, E., Sherman, E. M. S., \& Spreen, O. (2006). A Compendium of Neuropsychological Tests: Administration, Norms, and Commentary ( $3^{\text {rd }}$ ed.). Oxford, UK: Oxford University Press.

Troyer, A. K., Leach, L., \& Strauss, E. (2006). Aging and Response Inhibition: Normative Data for the Victoria Stroop Test. Aging, Neuropsychology, and Cognition, 13, 20-35. http://dx.doi.org/10.1080/138255890968187

Wagner, G., Sinsel, E., Sobanski, T., Köhler, S., Marinou, V., Mentzel, H. J., Schlösser, R. G. M. et al. (2006). Cortical Inefficiency in Patients with Unipolar Depression: An Event-Related fMRI Study with the Stroop Task. Biological Psychiatry, 59, 958-965. http://dx.doi.org/10.1016/j.biopsych.2005.10.025

Wagner, S., Doering, B., Helmreich, I., Lieb, K., \& Tadić, A. (2012). A Meta-Analysis of Executive Dysfunctions in Unipolar Major Depressive Disorder without Psychotic Symptoms and Their Changes during Antidepressant Treatment. Acta Psychiatrica Scandinavica, 125, 281-292. http://dx.doi.org/10.1111/j.1600-0447.2011.01762.x 